\title{
Microelectrochemical Characterization of the Effect of Rare Earth Inhibitors on the Localized Corrosion of AA2024-T3
}

\author{
Jichao Li, ${ }^{\mathrm{z}}$ Belinda Hurley, and Rudolph Buchheit* \\ Fontana Corrosion Center, Department of Materials Science and Engineering, The Ohio State University, Columbus, \\ Ohio 43210, USA
}

\begin{abstract}
The inhibition effect of three rare earth metals (REMs), $\mathrm{Ce}^{3+}, \mathrm{La}^{3+}$ and $\mathrm{Pr}^{3+}$, on the electrochemical properties of synthesized single-phase intermetallic compounds (IMCs) representing phases commonly found in AA2024-T3 were studied and compared with chromate inhibition. REM additions had little effect on corrosion potential, pitting potential and $\mathrm{i}_{\text {corr }}$ in short-term tests. This is in contrast to effects observed with chromate inhibitor additions where the pitting potential was seen to increase dramatically. All three REMs decreased the oxygen reduction reaction (ORR) kinetics on each synthesized phase, but none as much as chromate. The results in these studies are consistent with the idea that inhibition by REMs results from hydroxide precipitation at IMCs due to a local $\mathrm{pH}$ increase associated with the ORR. As hydroxide precipitation is a comparatively slow process, REMs cannot inhibit the initial dealloying of $\mathrm{S}$ phase, leading to the formation of dealloyed layers under hydroxide layers. Once the hydroxide precipitate forms, the subsequent corrosion of $\mathrm{S}$ phase is strongly inhibited. The dependence of inhibition on the formation of hydroxide deposits demonstrates that REMs are "slow" inhibitors, which must be considered in their applications.

(C) The Author(s) 2015. Published by ECS. This is an open access article distributed under the terms of the Creative Commons Attribution 4.0 License (CC BY, http://creativecommons.org/licenses/by/4.0/), which permits unrestricted reuse of the work in any medium, provided the original work is properly cited. [DOI: 10.1149/2.0791510jes] All rights reserved.
\end{abstract}

Manuscript submitted May 27, 2015; revised manuscript received July 27, 2015. Published August 7, 2015.

Alloying elements such as $\mathrm{Cu}$ and $\mathrm{Mg}$ are intentionally added to AA2024-T3 to improve mechanical properties such as strength and toughness. ${ }^{1}$ However, their solubility in $\mathrm{Al}$ is low and these elements precipitate to form intermetallic compound (IMC) particles during solidification processing and heat-treatment. ${ }^{1-3}$ These IMCs usually possess electrochemical properties different from the surrounding matrix, and can be selectively dissolved or induce localized galvanic corrosion. ${ }^{4-6}$ Passive or dealloyed films on an IMC particle surface can protect the particle from corrosion, but they can rupture or deteriorate under aggressive environmental conditions or mechanical stress, leading to increased electrochemical reactivity and localized corrosion. ${ }^{7-9}$ Inhibitors have been used to stifle the localized corrosion and improve corrosion resistance, thereby extending the service time of aluminum alloys. ${ }^{10}$ Chromate is a noteworthy inhibitor with the ability to self-heal if chemical or mechanical damage occurs. ${ }^{11-17}$ Unfortunately, chromate is toxic and carcinogenic in nature and its application is limited. There have been extensive efforts to develop environmentally friendly alternative inhibitors, and rare earth metals (REMs) such as cerium, praseodymium and lanthanum have attracted much attention. ${ }^{18-23}$

REM inhibition was first demonstrated in experiments with AA7075, wherein the ability to inhibit corrosion was evaluated by mass loss and linear polarization measurements. ${ }^{18}$ Corrosion rates were decreased dramatically by the addition of $100 \mathrm{ppm} \mathrm{CeCl}_{3}$, with the level of inhibition remaining constant up to $1000 \mathrm{ppm}$. Similar inhibition efficiencies and trends were observed for other lanthanide salts including $\mathrm{YCl}_{3}, \mathrm{LaCl}_{3}, \mathrm{PrCl}_{3}$ and $\mathrm{NdCl}_{3} .{ }^{24}$ In all cases, inhibition derives mainly from inhibition of oxygen reduction reaction (ORR) kinetics, and inhibition efficiency tends to increase with increasing immersion time. ${ }^{25}$ Inhibition is believed to result from precipitation of an REM-bearing hydroxide onto local cathodic sites, which initially support the ORR and promote a local $\mathrm{pH}$ increase. When the local $\mathrm{pH}$ exceeds a certain value, hydroxides precipitate on the cathodic sites ${ }^{25}$ blocking the ORR and suppressing the associated localized corrosion. ${ }^{20,26,27}$

Aside from soluble salts, ${ }^{21,25,28}$ other forms of REM inhibitors have also been investigated, including hydrotalcite-based coatings ${ }^{29}$ and REM conversion coatings. ${ }^{30-33}$ Most previous research was conducted using bulk aluminum alloys, and inhibition associated with localized corrosion was evaluated by observing the corrosion morphology and precipitation on second phase particles. However, the electrochemical interaction between individual IMCs and REM ions and the extent to

*Electrochemical Society Fellow.

${ }^{\mathrm{z}}$ E-mail: li.2037@osu.edu which REMs can inhibit oxygen reduction have not been characterized specifically. In this paper, the electrochemical characteristics of IMCs commonly found in AA2024-T3 during exposure to $0.1 \mathrm{NaCl}$ solution in the presence of REMs $\left(\mathrm{Ce}^{3+}, \mathrm{Pr}^{3+}, \mathrm{La}^{3+}\right)$ were studied using an electrochemical microcell method. REM inhibition effectiveness is compared with that of a chromate inhibitor.

\section{Experimental}

Sample and solution preparation.- The IMCs studied in this work were $\mathrm{Al}_{7} \mathrm{Cu}_{2} \mathrm{Fe}, \mathrm{Al}_{20} \mathrm{Cu}_{2} \mathrm{Mn}_{3}, \mathrm{Al}_{2} \mathrm{CuMg}$ ( $\mathrm{S}$ phase), and $\mathrm{Al}_{2} \mathrm{Cu}$. An $\mathrm{Al}-4$ wt.\% Cu solid solution alloy was also characterized as an analog for the matrix phase in AA2024-T3. Samples of these IMCs were specially synthesized, heat treated and characterized as discussed previously. ${ }^{6}$ All samples were ground to 1200 grit using SiC papers and ethanol as lubricant, and then polished using $1 \mu \mathrm{m}$ diamond paste lubricated with light-weight oil. Polished samples were ultrasonically cleaned in ethanol to remove any organic residue, air-dried and immediately used for corrosion experiments. A $0.1 \mathrm{M} \mathrm{NaCl}$ solution was prepared by dissolving reagent grade $\mathrm{NaCl}$ in deionized water with a resistivity of $18.2 \mathrm{M} \Omega \cdot \mathrm{cm}$. REM solutions of $\mathrm{Ce}^{3+}, \mathrm{La}^{3+}$, and $\mathrm{Pr}^{3+}$ were prepared at a concentration of $4 \mathrm{mM}$ by adding $\mathrm{CeCl}_{3}, \mathrm{LaCl}_{3}$ and $\mathrm{PrCl}_{3}$ (99.9\% pure) to $0.1 \mathrm{M} \mathrm{NaCl}$ solutions. Identical corrosion tests were also performed in a chromate solution. $\mathrm{RCl}_{3}$ solution ( $\mathrm{R}$ represents $\mathrm{Ce}^{3+}, \mathrm{La}^{3+}$, or $\left.\mathrm{Pr}^{3+}\right)$ in this paper refers to solutions containing $0.1 \mathrm{M} \mathrm{NaCl}$ plus $4 \mathrm{mM}$ REM salt, while the "chromate solution" refers to $0.1 \mathrm{M} \mathrm{NaCl}$ plus $1 \mathrm{mM} \mathrm{K}_{2} \mathrm{CrO}_{4}$.

Electrochemical measurements. - Anodic and cathodic polarization curves were collected on each IMC in each solution using the electrochemical microcell method. ${ }^{34}$ The diameters of the capillary tips were about $100 \mu \mathrm{m}$. All experiments were conducted using a Gamry Reference 600 potentiostat in a standard three-electrode setup with a saturated calomel electrode (SCE) as the reference electrode and a platinum wire as the counter electrode. The anodic polarization measurements were initiated from $-0.02 \mathrm{~V}$ vs. OCP, while cathodic polarization curves were initiated from $0.01 \mathrm{~V}$ vs. OCP. All scans were conducted at $2 \mathrm{mV} / \mathrm{s}$. Each measurement was repeated at least three times. Cathodic polarization measurements of $\mathrm{S}$ phase were initiated after a 1000 second exposure under free corrosion conditions so as to measure cathodic kinetics on a surface that was partially or fully dealloyed. Values for $\mathrm{i}_{\text {corr }}$ were determined by Tafel extrapolation of the linear region of the anodic polarization curves to the corrosion potential. 

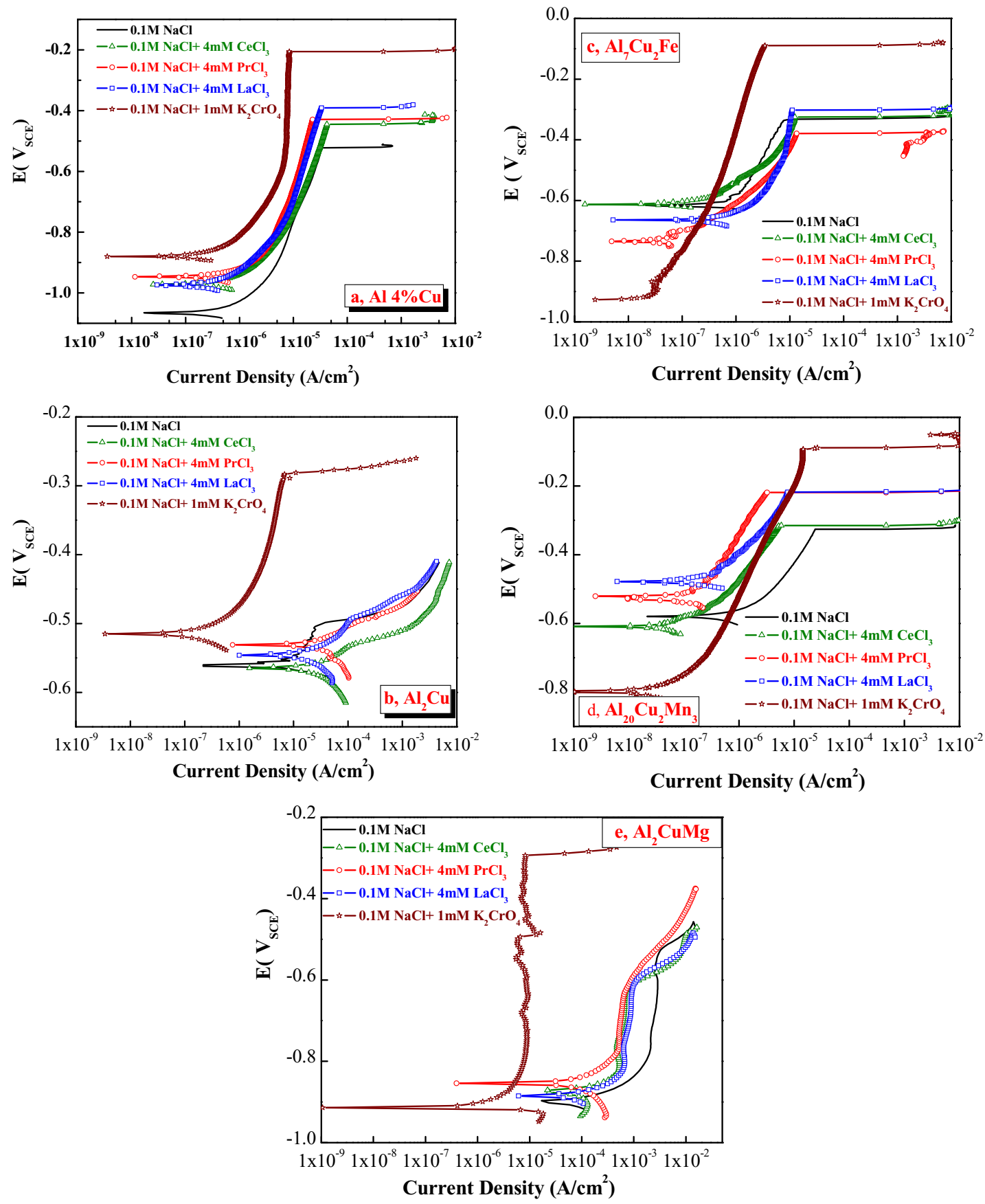

Figure 1. Representative anodic polarization curves of synthesized IMCs in $\mathrm{NaCl}, \mathrm{RCl}_{3}\left(\mathrm{R}\right.$ represents $\mathrm{Ce}^{3+}, \mathrm{La}^{3+}$ or $\left.\mathrm{Pr}^{3+}\right)$, and $\mathrm{K}_{2} \mathrm{CrO}_{4}$.

and corrosion product chemistry of AA2024-T3 after various exposure times in each REM solution and the chromate solution were examined using scanning electron microscopy (SEM) coupled with energy dispersive X-ray spectroscopy (EDS). Additionally, cross sections of dealloyed $S$ phase particles were prepared and examined using a focused ion beam (FIB) (30 kV Ga ion beam). Platinum was deposited on some particles before the milling process to avoid any damage from Ga ions. EDS mapping was performed on two kinds of IMCs in the alloy ( $\mathrm{Al}-\mathrm{Cu}-\mathrm{Mn}-\mathrm{Fe}$ particles and $\mathrm{S}$ phase) after 52.5 hours of exposure in $\mathrm{CeCl}_{3}$ solution at room temperature. The working distance of the SEM was $10 \mathrm{~mm}$ and the accelerating voltage was $20 \mathrm{kV}$.

To characterize the intensity of cerium deposition on Al-Cu-MnFe type particles and $\mathrm{S}$ phase particles, a cerium deposition intensity metric was calculated by dividing the integrated cerium EDS peak by the particle surface area. This cerium deposition intensity metric was then related to the cathodic kinetics on $\mathrm{Al}-\mathrm{Cu}-\mathrm{Mn}-\mathrm{Fe}$ type particles and $\mathrm{S}$ phase particles to characterize the relationship between cerium deposition and resulting inhibition.

\section{Results}

Electrochemical response of synthesized IMCs in $0.1 \mathrm{M} \mathrm{NaCl} \mathrm{solu-}$ tion with and without inhibitors. - Fig. 1 and Fig. 2 show anodic and cathodic polarization curves for the $\mathrm{Al}-4 \% \mathrm{Cu}$ solid solution, $\mathrm{Al}_{2} \mathrm{Cu}$, $\mathrm{Al}_{7} \mathrm{Cu}_{2} \mathrm{Fe}, \mathrm{Al}_{20} \mathrm{Cu}_{2} \mathrm{Mn}_{3}$ and $\mathrm{S}$ phase in each test solution. These representative polarization curves were selected from replicate measurements based on their proximity to the average value of corrosion potential $\left(\mathrm{E}_{\mathrm{corr}}\right)$ and pitting potential $\left(\mathrm{E}_{\mathrm{pit}}\right)$. The data for $\mathrm{E}_{\text {corr }}$ and $\mathrm{E}_{\mathrm{pit}}$ 

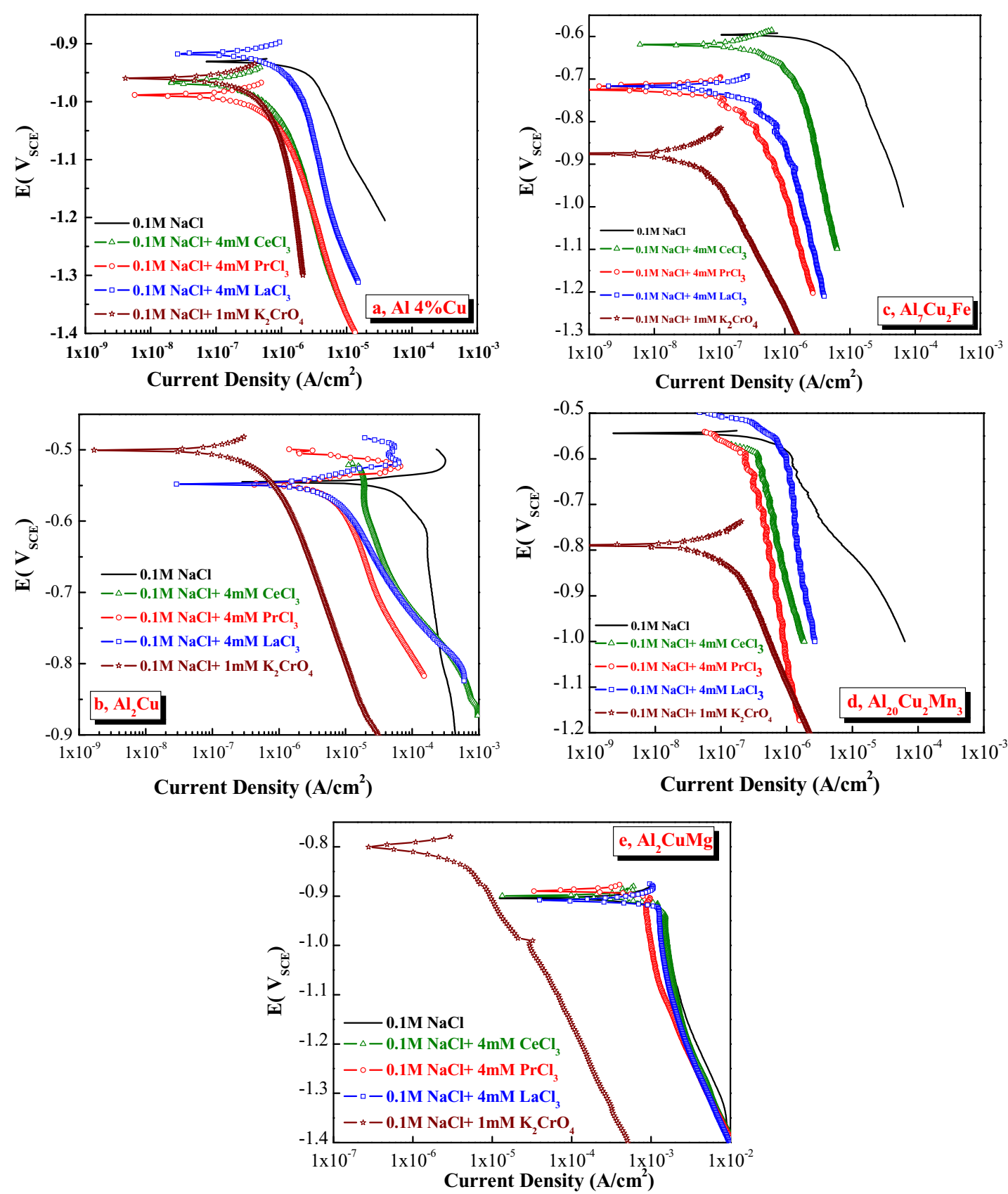

Figure 2. Representative cathodic polarization curves of synthesized IMCs in $\mathrm{NaCl}, \mathrm{RCl}_{3}\left(\mathrm{R}\right.$ represents $\mathrm{Ce}^{3+}, \mathrm{La}^{3+}$ or Pr $^{3+}$ ), and $\mathrm{K}_{2} \mathrm{CrO}_{4}$.

with error bars are summarized in Fig. 3, while Fig. 4 shows $i_{\text {corr }}$ values for each of the IMCs in each solution. Fig. 5 shows the limiting current densities at a given potential (noted on x-axis) obtained from the representative cathodic polarization curves in Fig. 2.

Al-4\%Cu. - With the addition of $4 \mathrm{mM} \mathrm{REM}$ salts in $0.1 \mathrm{M} \mathrm{NaCl}$, both $\mathrm{E}_{\text {corr }}$ and $\mathrm{E}_{\text {pit }}$ were increased on $\mathrm{Al}-4 \% \mathrm{Cu}$ and $\mathrm{i}_{\text {corr }}$ was slightly reduced (Fig. 3 and Fig. 4). Among the three REM inhibitors, average values show that $\operatorname{Pr}^{3+}$ was the most effective in reducing $i_{\text {corr }}$ but $\mathrm{La}^{3+}$ was the most effective in raising the pitting potential (Fig. 4 and Fig 3, respectively). $\mathrm{E}_{\text {corr }}$ of $\mathrm{Al}-4 \% \mathrm{Cu}$ in $0.1 \mathrm{M} \mathrm{NaCl}$ was reproducible and fell within a small band (about $30 \mathrm{mV}$ ) as shown in Fig. 3. Overall, the inhibition of anodic behavior observed on the solid solution alloy was modest. On the other hand, when this alloy was exposed to chromate, both $\mathrm{E}_{\text {corr }}$ and $\mathrm{E}_{\text {pit }}$ were increased by about 0.2 and $0.3 \mathrm{~V}$, respectively, and $i_{\text {corr }}$ was reduced by a factor of about 3 . As shown in Fig. 2, cathodic reaction kinetics were considerably inhibited by the addition of REMs and chromate, but to different extents. Both $\mathrm{Ce}^{3+}$ and $\mathrm{Pr}^{3+}$ reduced the ORR by a factor of about 6 , while $\mathrm{La}^{3+}$ did so by a factor of about 3 (Fig. 5). Chromate was most effective, reducing the ORR rate by an order of magnitude.

$\mathrm{Al}_{2} \mathrm{Cu}$.- There was no obvious anodic inhibition of $\mathrm{Al}_{2} \mathrm{Cu}$ by the addition of REM inhibitors, as shown in Fig. 1b. In both $\mathrm{NaCl}$ and REMcontaining solutions, $\mathrm{E}_{\text {corr }}$ and $\mathrm{E}_{\text {pit }}$ were similar, about $-0.55 \mathrm{~V}_{\mathrm{SCE}}$ and $-0.51 \mathrm{~V}_{\mathrm{SCE}}$, respectively (Fig. 3). $\mathrm{E}_{\mathrm{corr}}$ and $\mathrm{E}_{\mathrm{pit}}$ in all REM solutions on this IMC were reproducible within a $45 \mathrm{mV}$ window. A slightly higher $\mathrm{i}_{\text {corr }}$ was observed in the REM solutions compared to that in $\mathrm{NaCl}$-only solution (Fig. 4). The response in chromate solution was distinct from that in $\mathrm{NaCl}$ and REM solutions. Chromate increased $\mathrm{E}_{\mathrm{pit}}$ by $0.18 \mathrm{~V}$ and reduced $i_{\text {corr }}$ by a factor of about 40 compared to $\mathrm{NaCl}$. It should be noted that for this IMC in chromate, $\mathrm{E}_{\mathrm{pit}}$ varied over a range of $110 \mathrm{mV}$ in replicate measurements. Strong inhibition of cathodic kinetics was observed with the addition of REM inhibitors on $\mathrm{Al}_{2} \mathrm{Cu}$ (Fig. 2b). 


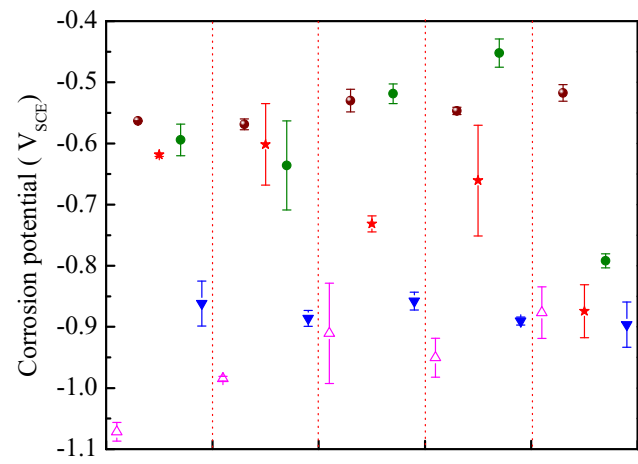

$\triangle \mathrm{Al} 4 \% \mathrm{Cu}$

- $\mathrm{Al}_{2} \mathrm{Cu}$

* $\mathrm{Al}_{7} \mathrm{Cu}_{2} \mathrm{Fe}$

- $\mathrm{Al}_{20} \mathrm{Cu}_{2} \mathrm{Mn}_{3}$

- $\mathrm{Al}_{2} \mathrm{CuMg}$

0.1M NaCl + None $4 \mathrm{mM} \mathrm{CeCl}_{3} 4 \mathrm{mM} \mathrm{PrCl}_{3} \quad 4 \mathrm{mM} \mathrm{LaCl}_{3} \quad 1 \mathrm{mM} \mathrm{K}_{2} \mathrm{CrO}$

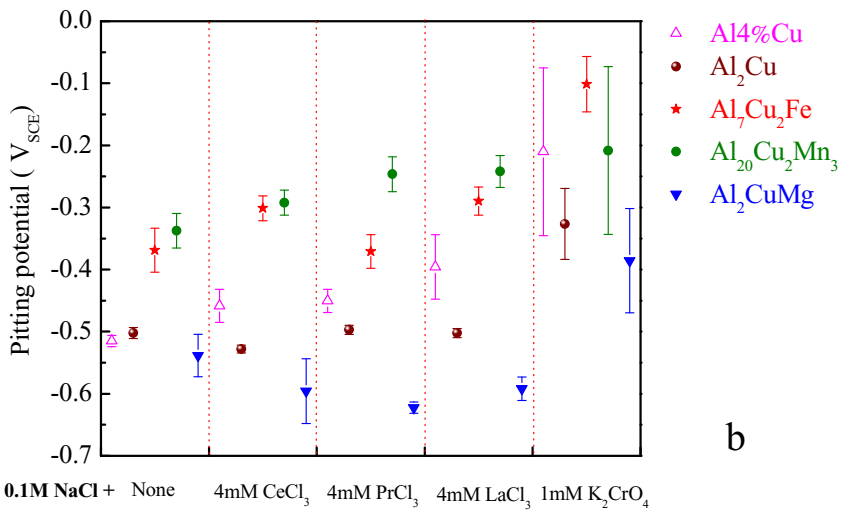

Figure 3. Corrosion potential (a) and pitting potential (b) of synthesized IMCs in $\mathrm{NaCl}, \mathrm{RCl}_{3}$ ( $\mathrm{R}$ represents $\mathrm{Ce}^{3+}, \mathrm{La}^{3+}$ or $\mathrm{Pr}^{3+}$ ), and $\mathrm{K}_{2} \mathrm{CrO}_{4}$.

$\mathrm{Ce}^{3+}$ and $\mathrm{La}^{3+}$ showed similar inhibition efficiency, reducing the cathodic current by a factor of about 3 , while $\mathrm{Pr}^{3+}$ praseodymium reduced the ORR by a factor of about 7 (Fig. 5). Clearly, however, inhibition by chromate was much stronger than REM inhibition.

$\mathrm{Al}_{7} \mathrm{Cu}_{2} \mathrm{Fe}$. - On $\mathrm{Al}_{7} \mathrm{Cu}_{2} \mathrm{Fe}, \mathrm{E}_{\text {corr }}$ in $\mathrm{CeCl}_{3}$ and $\mathrm{LaCl}_{3}$ solutions was similar to that in $0.1 \mathrm{M} \mathrm{NaCl}$, but it was decreased by $0.1 \mathrm{~V}$ in the $\mathrm{PrCl}_{3}$ solution (Figs. 2c and 3a). The $\mathrm{Pr}^{3+}$ addition did not have much of an effect on $\mathrm{E}_{\text {pit }}$ while $\mathrm{Ce}^{3+}$ and $\mathrm{La}^{3+}$ increased $\mathrm{E}_{\text {pit }}$ by about $70 \mathrm{mV}$. Fig. 3 reveals a large distribution of $E_{\text {corr }}$ values in REM inhibitor solutions on $\mathrm{Al}_{7} \mathrm{Cu}_{2} \mathrm{Fe}$ (hundreds of $\mathrm{mV}$ ), while a smaller distribution is observed for $\mathrm{E}_{\text {pit }}(60 \mathrm{mV})$. All the REMs reduced $\mathrm{i}_{\text {corr }}$

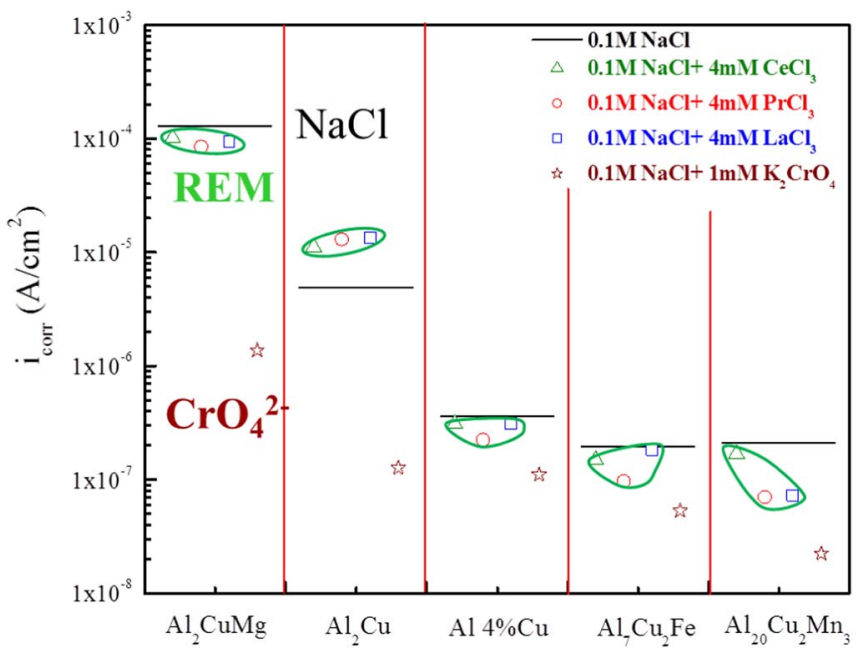

Figure 4. Comparison of $\mathrm{i}_{\text {corr }}$ in $\mathrm{NaCl}, \mathrm{RCl}_{3}\left(\mathrm{R}\right.$ represents $\mathrm{Ce}^{3+}, \mathrm{La}^{3+}$ or $\mathrm{Pr}^{3+}$ ), and $\mathrm{K}_{2} \mathrm{CrO}_{4}$. The horizontal line represents $\mathrm{i}_{\text {corr }}$ in $0.1 \mathrm{M} \mathrm{NaCl}$.

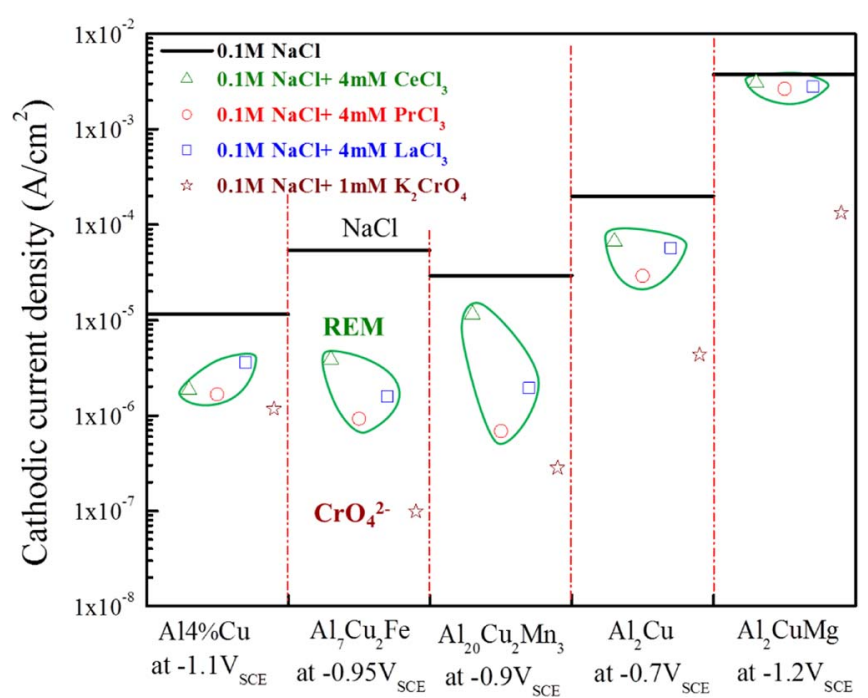

Figure 5. Cathodic current density comparison in $\mathrm{NaCl}, \mathrm{RCl}_{3}$ ( $\mathrm{R}$ represents $\mathrm{Ce}^{3+}, \mathrm{La}^{3+}$ or $\mathrm{Pr}^{3+}$ ), and $\mathrm{K}_{2} \mathrm{CrO}_{4}$.

slightly with $\mathrm{Pr}^{3+}$ being the most effective with a reduction in rate by a factor of about 2 (Fig. 4). Compared to $0.1 \mathrm{M} \mathrm{NaCl}$, chromate increased $\mathrm{E}_{\text {pit }}$ by $0.27 \mathrm{~V}$, reduced $\mathrm{E}_{\text {corr }}$ by $0.26 \mathrm{~V}$ and lowered $\mathrm{i}_{\text {corr }}$ by a factor of about 4. All REMs strongly inhibited ORR kinetics in the decreasing order: $\mathrm{Pr}^{3+}>\mathrm{La}^{3+}>\mathrm{Ce}^{3+}$ (Fig. 5), but they were less efficient than chromate, which reduced ORR kinetics by a factor of 500.

$\mathrm{Al}_{20} \mathrm{Cu}_{2} \mathrm{Mn}_{3}$. - Relative to the $\mathrm{NaCl}$ solution, $\mathrm{E}_{\mathrm{pit}}$ on $\mathrm{Al}_{20} \mathrm{Cu}_{2} \mathrm{Mn}_{3}$ was increased by about 45 to $95 \mathrm{mV}$ in all three REM solutions, while $\mathrm{E}_{\text {corr }}$ was increased by about 77 to $144 \mathrm{mV}$ in $\mathrm{PrCl}_{3}$ and $\mathrm{LaCl}_{3}$ solutions but decreased slightly in $\mathrm{CeCl}_{3}$ solution (Fig. 3). $\mathrm{E}_{\text {pit }}$ data were reasonably reproducible in REM solutions, while a large distribution in $\mathrm{E}_{\text {corr }}$ was observed (20-109 mV). Decreased $i_{\text {corr }}$ values in REM inhibitor solutions were also observed, with $\operatorname{Pr}^{3+}$ being the most effective (Fig. 4). Again, chromate provided the strongest inhibition with a reduction factor of about 10 in $\mathrm{i}_{\text {corr }}$ and ennoblement of $130 \mathrm{mV}$ in $\mathrm{E}_{\text {pit }}$, compared to that in a $\mathrm{NaCl}$ solution. The ORR on $\mathrm{Al}_{20} \mathrm{Cu}_{2} \mathrm{Mn}_{3}$ was reduced by a factor of about 2 to 40 in REM inhibitor solutions with $\mathrm{Pr}^{3+}$ being the most effective, but still it is not as effective as chromate, which reduces the ORR kinetics by more than two orders of magnitude (Fig. 5). The inhibition efficiencies of REMs became more obvious as the potential moved lower than $-0.8 \mathrm{~V}_{\mathrm{SCE}}$, where $\operatorname{Pr}^{3+}$ provided inhibition efficiency comparable to chromate (Fig. 2d).

$\mathrm{Al}_{2} \mathrm{CuMg}$ (S phase).-The corrosion behavior of S phase, arguably the IMC of most interest, is complex. It has an active $\mathrm{E}_{\text {corr }}$ and initially corrodes by dealloying. Dealloying corrosion results in a porous $\mathrm{Cu}$-rich layer that ennobles $\mathrm{S}$ phase and supports the ORR at an increased rate. ${ }^{35-38}$ During the formation of this $\mathrm{Cu}$-rich surface layer, polarization measurements can differ significantly due to the changing nature of the composition of the $S$ phase surface. ${ }^{6,39-41}$ To suppress initial dealloying of $\mathrm{S}$ phase, prompt inhibiting action is needed. However, no obvious effects were observed on $\mathrm{E}_{\text {corr }}, \mathrm{E}_{\text {pit }}$ and $\mathrm{i}_{\text {corr }}$ by addition of REM inhibitors (Fig. 1e), suggesting that REM inhibitors do not act fast enough to inhibit dealloying corrosion and the associated formation of a Cu-rich layer. Therefore, to determine the inhibition efficiency of REMs on the ORR that occurs on the $\mathrm{Cu}$-rich layer, cathodic polarization curves in all solutions were collected after 1000 seconds of pre-exposure under free corrosion conditions (Fig. 6). The OCP values of $\mathrm{S}$ phase in REM inhibitor solutions are similar, about $-915 \mathrm{mV}_{\mathrm{SCE}}$, which is slightly more positive than that in $\mathrm{NaCl}$ but lower than that in chromate. As shown in Fig. 2e, dealloyed S phase supports the ORR at a rate that is two or three orders of magnitude larger than on other IMCs in $\mathrm{NaCl}$. Chromate increases $\mathrm{E}_{\text {pit }}$ by $150 \mathrm{mV}$ (Fig. 3) and $i_{\text {corr }}$ is reduced by two orders of magnitude, while 


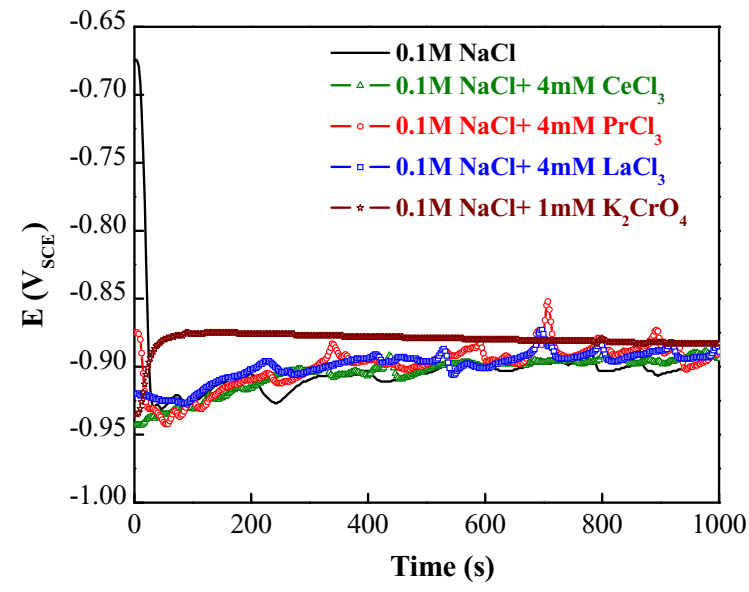

Figure 6. $\mathrm{OCP}$ of synthesized $\mathrm{S}$ phase in $\mathrm{NaCl}, \mathrm{RCl}_{3}$ ( $\mathrm{R}$ represents $\mathrm{Ce}^{3+}$, $\mathrm{La}^{3+}$ or $\mathrm{Pr}^{3+}$ ), and $\mathrm{K}_{2} \mathrm{CrO}_{4}$.

the ORR is reduced by a factor of about 30 compared to that in $0.1 \mathrm{M}$ $\mathrm{NaCl}$.

Localized corrosion morphology of AA2024-T3 after 50 hours immersion in $\mathrm{NaCl}$ and inhibitor solutions. - To relate the electrochemistry data collected from synthesized IMCs to corrosion that occurs on AA2024-T3, the corrosion morphology was examined by SEM after free corrosion exposures in each solution (Fig. 7).
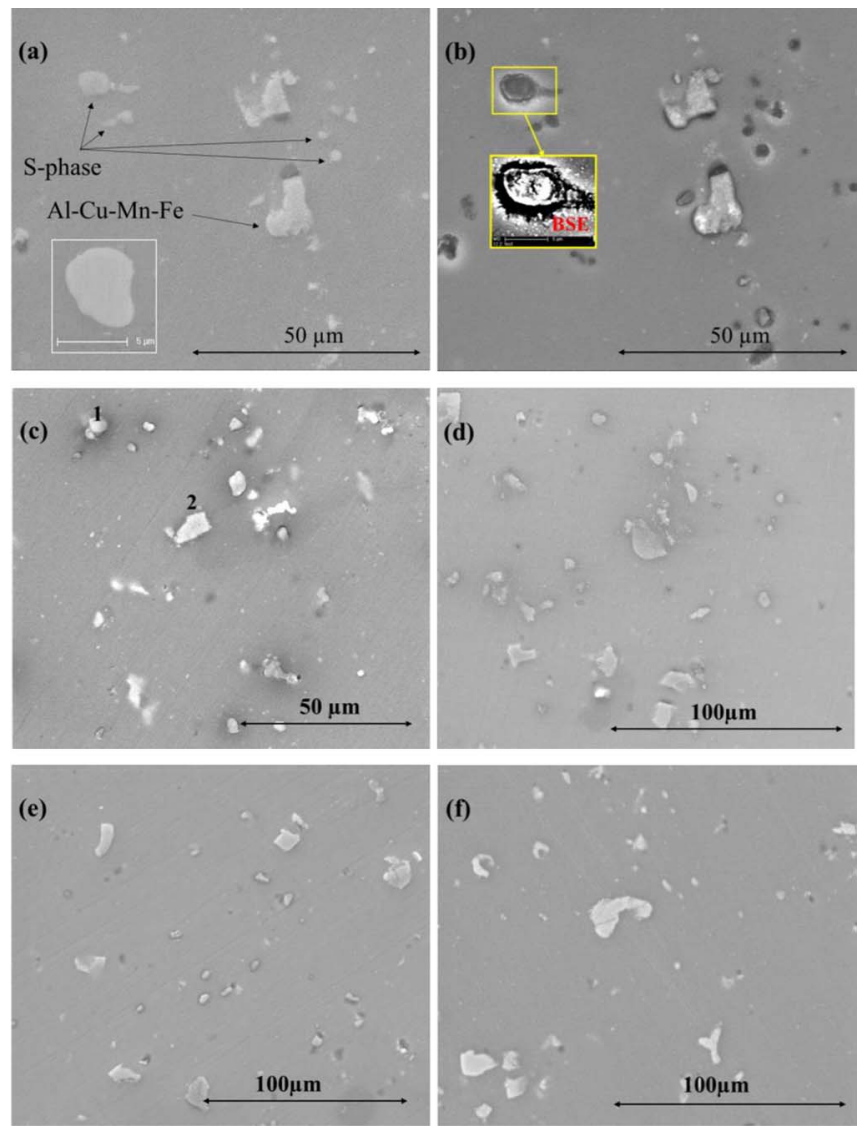

Figure 7. Corrosion morphology of AA2024-T3: (a) after polishing (insert is magnified $\mathrm{S}$ phase); (b) after 6 hours exposure in $0.1 \mathrm{M} \mathrm{NaCl}$ (insert is magnified backscattered electron image of S-phase); (c) 50 hours in a $\mathrm{CeCl}_{3}$ solution; (d) 50 hours in a $\mathrm{LaCl}_{3}$ solution; (e) 50 hours in a $\mathrm{PrCl}_{3}$ solution; (f) 50 hours in a $\mathrm{K}_{2} \mathrm{CrO}_{4}$ solution.
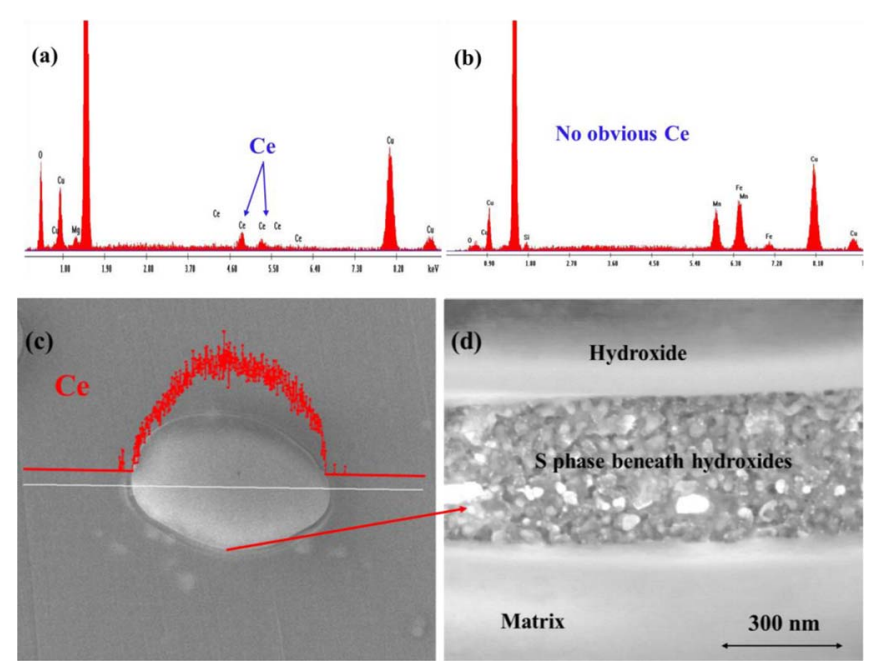

Figure 8. EDS spectra: (a) Point 1 in Fig. 7a; (b) Point 2 in Fig. 7a; (c) EDS line scanning across an S phase particle; (d) magnified SEM image of the edge gap in (c).

Fig. 7a reveals the heterogeneous microstructure of polished AA2024$\mathrm{T} 3$, which includes $\mathrm{Al}-\mathrm{Cu}-\mathrm{Mn}-\mathrm{Fe}$ type and $\mathrm{S}$ phase particles. Rounded $\mathrm{S}$ phase particles are relatively small with a diameter less than $5 \mu \mathrm{m}$ (as shown magnified in the inset of Fig. 7a). All localized corrosion was associated with IMC particles as shown in the corrosion morphology present after 6 hours immersion in $\mathrm{NaCl}$ at room temperature (Fig. 7b). Al-Cu-Mn-Fe type particles generally displayed trenching corrosion along the interface between the particle and the surrounding matrix. Many S phase particles completely dissolved, forming a pit, while others displayed trenching corrosion around the dealloyed $S$ phase remnant, as shown in the backscattered electron (BSE) image (Fig. 7b inset). With the addition of REMs, localized corrosion was strongly inhibited as shown in Figs. 7c, 7d, and 7e, even when the exposure time was extended to 50 hours. Although slight corrosion was still observed on $\mathrm{S}$ phase particles, trenching corrosion around $\mathrm{Al}-\mathrm{Cu}-\mathrm{Mn}-\mathrm{Fe}$ type particles was suppressed. Figs. $8 \mathrm{a}$ and $8 \mathrm{~b}$ present EDS spectra on two kinds of particles (points 1 and 2 in Fig. 7c, exposure in a $\mathrm{CeCl}_{3}$ solution). These spectra indicate the presence of cerium on the $\mathrm{S}$ phase particle (point 1 ) but little on the $\mathrm{Al}-\mathrm{Cu}-\mathrm{Mn}-\mathrm{Fe}$ type particle (point 2). EDS line scanning across the $\mathrm{S}$ phase particle (Fig. 8c) revealed that while cerium was concentrated on the $S$ phase particle, it was not detected to any significant extent on the matrix. Cerium forms a rounded cap on the $\mathrm{S}$ phase particles as observed in Fig. 8c and Fig. 9d. A gap between the precipitated cerium product and the matrix was observed along the edge of the S phase IMC, presumably due to dehydration arising from the high vacuum conditions of the SEM chamber. This gap permitted an observation of the morphology of the $\mathrm{S}$ phase particle along the edge of the precipitation as shown in Fig. 8d. Presumably, if the gap arose from dehydration, this morphology represents the state of the $S$ phase particle under the entire cerium precipitate. As expected, the $S$ phase particle underwent severe dealloying corrosion as indicated by the presence of fine nanoscale $\mathrm{Cu}$ granules. The heterogeneous nature of the dealloyed $\mathrm{S}$ phase (Fig. 8d) suggests the presence of perhaps a substance intermixed with the $\mathrm{Cu}$ granules, possibly $\mathrm{Ce}(\mathrm{OH})_{3}$. In contrast, no localized attack was observed on samples after exposure in chromate solution as shown in Fig. 7f.

Cross-sectional observation of $S$ phase and cerium precipitation after different exposure times in a $\mathrm{CeCl}_{3}$ solution. - Although a considerable amount of cerium was observed to precipitate on $\mathrm{S}$ phase and form a protective cap, dealloying corrosion still occurred as observed in the gap along the edge of the IMC. The cerium precipitate covering $S$ phase particles makes it difficult to observe the extent of dealloying corrosion of an entire $\mathrm{S}$ phase particle. Therefore, cross-sectional 


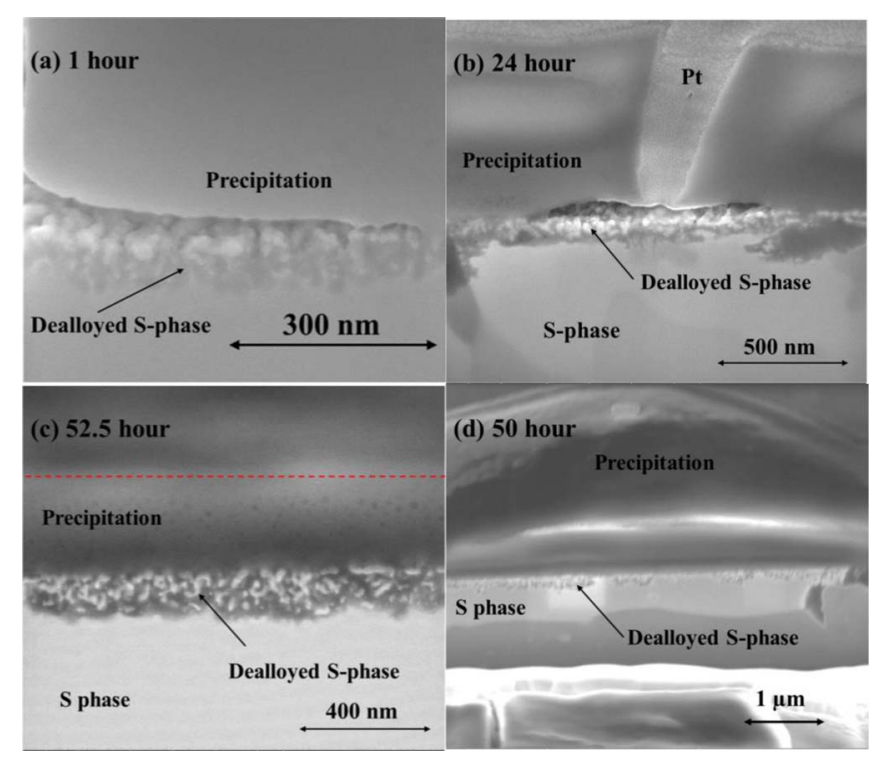

Figure 9. Cross-section SEM of S phase after different exposure times in a $\mathrm{CeCl}_{3}$ solution.

analysis by FIB was undertaken. This analysis clearly revealed the thickness of dealloyed S phase (Fig. 9). The typical structure of S phase particles after exposure to the $\mathrm{Ce}^{3+}$ solution was found to consist of 1 the cerium precipitate (presumably a hydroxide), 2 dealloyed $\mathrm{S}$ phase and 3 un-corroded $\mathrm{S}$ phase. The thickness of the dealloyed $\mathrm{S}$ phase increased from $100 \mathrm{~nm}$ to $130 \mathrm{~nm}$ as the immersion time increased from 1 to 52.5 hours. This suggests the dealloying corrosion occurs rapidly during initial exposure, but is soon strongly inhibited. The cerium hydroxide layer thickness was about $230 \mathrm{~nm}$ after 1 hour immersion and increased only slightly to $240 \mathrm{~nm}$ after 52.5 hours. This slow growth rate indicates hydroxide layer formation occurs early during exposure and subsequent formation is limited. The dispersed voids visible in the structure of the $\mathrm{Ce}^{3+}$ precipitate (Fig. 9c) suggest a non-compact structure. The loose packed nature of the precipitate appears to allow the continuous slow growth of the precipitate layer and the propagation of dealloying corrosion. This porosity would allow dissolved oxygen to reach the interface and maintain the corrosion process at a slow rate.

\section{Discussion}

Effect of REMs on $E_{\text {corr }}, E_{\text {pit }}$ and $i_{\text {corr }}$ - - Fig. 10 shows the plot of average values of $E_{\text {pit }} v s$. $E_{\text {corr }}$, in which each circle represents one of the synthesized IMCs. $E_{\text {pit }}$ and $E_{\text {corr }}$ data in $0.1 \mathrm{M} \mathrm{NaCl}$ and the three REM solutions ( $4 \mathrm{mM} \mathrm{Ce}{ }^{3+}, \mathrm{La}^{3+}, \mathrm{Pr}^{3+}$ ) are enclosed in a circle for each IMC, while the data in the chromate solution are represented by a solid dot and connected to each circle by a dashed line. All the data are in the top-left portion of the plot where $\mathrm{E}_{\mathrm{pit}}>\mathrm{E}_{\mathrm{corr}}$, indicating that the synthesized IMCs showed passive behavior to some extent in all solutions. The closer a data point is to the dashed line, the smaller the passive range for the associated material. Compared to the data in $0.1 \mathrm{M} \mathrm{NaCl}, \mathrm{E}_{\text {pit }}$ and $\mathrm{E}_{\text {corr }}$ in the three REM solutions do not change much; 2 to $119 \mathrm{mV}$ and 5 to $160 \mathrm{mV}$, respectively. The negligible effect of REM inhibitors is also demonstrated from the small size of each circle, which encloses the data in $\mathrm{NaCl}$ and REM-containing solutions. This indicates that REM inhibitors do not significantly affect $\mathrm{E}_{\mathrm{pit}}$ and $\mathrm{E}_{\text {corr }}$ in short-term experiments. On the other hand, chromate inhibitor shifts the data far from each circle and $\mathrm{E}_{\text {pit }}$ values are dramatically increased for each IMC, indicating that chromate is a strong anodic inhibitor for IMC particles.

In Fig. $4, \mathrm{i}_{\text {corr }}$ values in $0.1 \mathrm{M} \mathrm{NaCl}$ are plotted as black horizontal lines, while $i_{\text {corr }}$ values in REM and chromate solutions are represented by discreet solid data points. The data in REM inhibitor

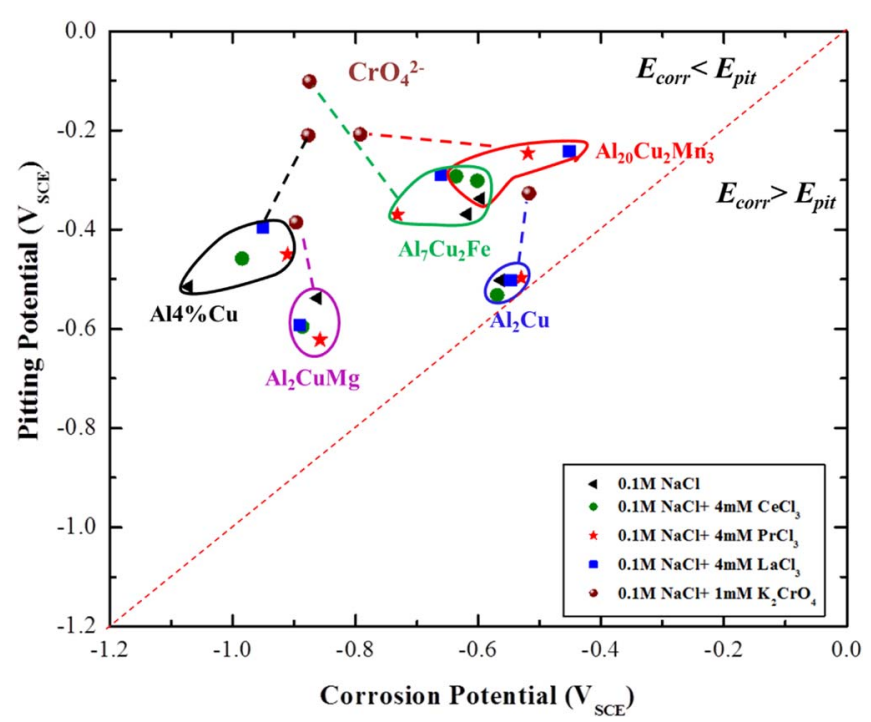

Figure 10. Relationship between the pitting potential and corrosion potential of IMCs in each test solution.

solutions are also circumscribed with a circle. As indicated by the displacement of the data points below the reference line, REM inhibitors slightly decreased $i_{\text {corr }}$ of all IMCs except $\mathrm{Al}_{2} \mathrm{Cu}$. The reason $\mathrm{i}_{\text {corr }}$ of $\mathrm{Al}_{2} \mathrm{Cu}$ increased is not clear, but its proximity to the reference line suggests it is within the uncertainty of the averaged measurements. The approximate nature of these averaged $i_{\text {corr }}$ values obtained in each REM inhibitor solution relative to that in a $\mathrm{NaCl}$ solution indicates that REMs do not have a significant effect on $\mathrm{i}_{\text {corr }}$ in these types of corrosion measurements. As indicated by the great distance between the chromate data and the reference line, chromate shows strong inhibition on $i_{\text {corr }}$.

The negligible effect on $\mathrm{E}_{\text {corr }}, \mathrm{E}_{\text {pit }}$ and $\mathrm{i}_{\text {corr }}$ suggests that REM inhibitors do not have a strong direct effect on anodic kinetics of second phase particles. It should be remembered that in microcell measurements the galvanic coupling of IMC to alloy, which leads to a local $\mathrm{pH}$ increase and hence the stimulation of REM precipitation and inhibition on bulk AA2024-T3, is not present, and the effect of stimulated REM precipitation on anodic kinetics is not captured.

Effect of REM inhibitors on cathodic kinetics of IMCs. - Fig. 5 shows the limiting current densities at a given potential (noted on $\mathrm{x}$-axis) obtained from the representative cathodic polarization curves in Fig. 2. These current densities were used to assess the inhibition efficiency of each REM inhibitor on the ORR. The symbols in Fig. 5 have the same meaning as those in Fig. 4, with a horizontal line presenting data in a $\mathrm{NaCl}$ solution. All three REM inhibitors suppress the ORR on each of IMCs. The extent of inhibition varied by a factor of 3 to 60 . Among the three REM inhibitors, $\mathrm{Pr}^{3+}$ was most effective, followed by $\mathrm{La}^{3+}$ and $\mathrm{Ce}^{3+}$. An exception was noted on $\mathrm{Al}-4 \% \mathrm{Cu}$ solid solution, for which $\mathrm{Ce}^{3+}$ provided better inhibition than $\mathrm{La}^{3+}$. Furthermore, the inhibition efficiency of $\operatorname{Pr}^{3+}$ on $\mathrm{Al}_{20} \mathrm{Cu}_{2} \mathrm{Mn}_{3}$ and Al$4 \% \mathrm{Cu}$ was comparable to that of chromate. The inhibition most likely results from the precipitated REM hydroxides formed on the surface, retarding the ORR. The minimum $\mathrm{pH}$ required to trigger hydroxide precipitation is dependent on the solubility product of each REM hydroxide. For example, in $4 \mathrm{mM}$ REM solutions, $\mathrm{Ce}(\mathrm{OH})_{3}$ starts to precipitate at $\mathrm{pH} 8.2$ (solubility product constant of $2 \times 10^{-19}$ ), while $\operatorname{Pr}(\mathrm{OH})_{3}$ precipitates at $\mathrm{pH} 6.98$ (solubility product constant of $\left.3.39 \times 10^{-24}\right) .{ }^{42}$ This means that more praseodymium-containing precipitation is expected than cerium-containing precipitation at neutral and slightly alkaline environments under steady-state conditions. The amount of precipitation is expected to correlate with the extent of inhibition, but the morphology of the precipitation is also important. Cerium hydroxide deposits contain many small pores, as can be 
seen in Fig. 9c and as consistent with reports in the literature. ${ }^{43} \mathrm{Al}-$ though the porosity of praseodymium precipitation was not explored, the porosity of the cerium precipitate combined with the likelihood of additional praseodymium precipitation arising from the lower solubility product constant of praseodymium offers some insight into why praseodymium is more efficient than cerium as an inhibitor.

For the dealloyed S phase, only slight inhibition is observed for all three REMs. The severe dealloying corrosion that occurs on $\mathrm{S}$ phase during a $1000 \mathrm{~s}$ immersion leads to the subsequent formation of a porous nano-scale $\mathrm{Cu}$-rich layer with a high surface area capable of supporting the ORR. This is reflected in the enhanced cathodic current observed on S phase (Fig. 2e). The porous, high surface area on $\mathrm{S}$ phase could lead to distortions in inhibition measurements obtained with the microcell setup due to the restricted electrolyte flow and restricted diffusion of oxygen and REM inhibitors. The restricted flow and diffusion most probably leads to a limited supply of REM inhibitor, which in turn leads to insufficient precipitation over the high surface area on porous $S$ phase.

The polarization measurements carried out in the microcell enable the effect of REMs on the anodic and cathodic polarization response to be isolated. However, these measurements do not capture well the effect of REM hydroxide that is stimulated by the local $\mathrm{pH}$ increase associated with local cathodic activity at particles in the alloy. So while exposure experiments (Fig. 7) clearly show that localized corrosion associated with $S$ phase particles is strongly inhibited by REMs, it appears that REM inhibition is only partially captured by microcell measurements.

A model to simulate the $\mathrm{pH}$ distribution around cathodic particles. - The inhibition at IMCs is attributed to hydroxide precipitation on the surface, which is a consequence of the local $\mathrm{pH}$ increase arising from the ORR at cathodic sites. With the exception of synthesized S phase, REM inhibitors displayed strong inhibition of ORR kinetics on synthesized IMCs when analyzed with the microcell (Fig. 2) and strong inhibition of localized corrosion was observed around S phase particles when AA2024-T3 was exposed in REM solutions. The $\mathrm{pH}$ distribution around cathodic particle sites should strongly affect the location and distribution of precipitated hydroxides and the associated protection. Therefore, it is important to understand the relationship between the $\mathrm{pH}$ distribution and ORR kinetics on IMCs. Based on the cathodic current density in $0.1 \mathrm{M} \mathrm{NaCl}$ solution (Fig. 2e), a simple model was constructed to simulate the $\mathrm{pH}$ distribution in the steady state around an S phase particle (Fig. 11).

Assumptions made in this steady state model: (a) The hydroxyl ions produced on the surface of an S phase particle due to the ORR diffuse uniformly into a hemispherical volume from a point in the center of the assumed circular surface of an S phase particle; (b) The hydroxyl ion generation rate is calculated using the limiting cathodic current density obtained from the cathodic polarization curve for $\mathrm{S}$ phase in the $\mathrm{NaCl}$ solution (Fig. 2e). Based on a four electron oxygen reduction process and Faraday's law:

$$
\begin{gathered}
\mathrm{O}_{2}+2 \mathrm{H}_{2} \mathrm{O}+4 e^{-} \leftrightharpoons 4 \mathrm{OH}^{-} \\
m_{O H^{-}}=4 \frac{i_{\text {cath }}}{n F} \pi r^{2}
\end{gathered}
$$

where $m_{\mathrm{OH}-}$ is the generation rate of hydroxyl ions ( $\left.\mathrm{mol} / \mathrm{s}\right), \mathrm{i}_{\text {cath }}$ is the limiting cathodic current density, $2.27 \times 10^{-3} \mathrm{~A} / \mathrm{cm}^{2}, \mathrm{n}$ is the number of equivalents per mole of $\mathrm{O}_{2}(4 \mathrm{eq} / \mathrm{mol}), \mathrm{r}$ is the radius of a spherical $\mathrm{S}$ phase particle (m), and $\mathrm{F}$ is Faraday's constant.

Assuming uniform diffusion, the diffusion rate of hydroxyl ions through the boundary shell of the assumed hemispherical diffusion volume at a boundary distance of $\mathrm{R}_{\mathrm{x}}$ can be calculated via Fick's first law:

$$
m_{D_{x}}=2 \pi R_{x}^{2}\left(-\left.D \frac{d C_{O H^{-}}}{d R}\right|_{R=R_{x}}\right)
$$

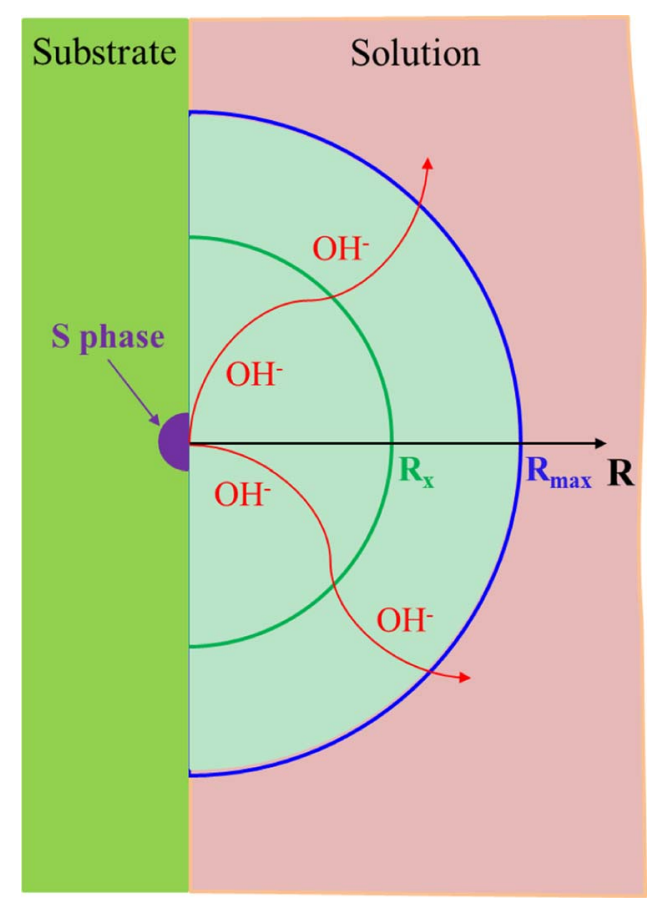

Figure 11. Model used to calculate the $\mathrm{pH}$ distribution around IMCs.

where $m_{D_{x}}$ is the diffusion rate through the hemisphere boundary at $\mathrm{R}_{\mathrm{x}}$ (moles $\mathrm{OH}^{-} / \mathrm{sec}$ ), D is the diffusion coefficient of $\mathrm{OH}^{-}$; taken to be $5.27 \times 10^{-9} \mathrm{~m}^{2} / \mathrm{s},{ }^{44,45}$ and $\frac{d C_{O H^{-}}}{d R}$ is the concentration gradient of $\mathrm{OH}^{-}$ along the radius of the diffusion hemisphere (with $\mathrm{R}_{\max }$ representing the assumed maximum radius of the diffusion hemisphere as noted in Fig. 11).

Under steady state conditions, the $\mathrm{OH}^{-}$generation rate $\left(m_{\mathrm{OH}^{-}}\right)$is equal to the diffusion rate $\left(m_{D_{x}}\right)$ of $\mathrm{OH}^{-}$through the moving hemisphere boundary shell. Setting Eq. 2 equal to Eq. 3 and integrating along the radius of the hemisphere provides the concentration of $\mathrm{OH}^{-}$, $\mathrm{C}_{\mathrm{OH}-}(\mathrm{mol} / \mathrm{L})$ as a function of distance from the center of the particle $\left(\mathrm{R}_{\mathrm{x}}\right)$ :

$$
C_{O H^{-}}=2.2 r^{2}\left(\frac{1}{R_{x}}-\frac{1}{R_{\max }}\right)
$$

where $\mathrm{r}$ is assumed to be $2.5 \times 10^{-6} \mathrm{~m}$ (Fig. 7a); $\mathrm{R}_{\max }$, the assumed maximum radius of the diffusion hemisphere, is taken as $10 \mu \mathrm{m},{ }^{37}$ and $\mathrm{C}_{\mathrm{OH}-}$ at $\mathrm{R}_{\max }$ is assumed to be negligible $\left(5 \times 10^{-9} \mathrm{M}\right.$, the concentration of $\mathrm{OH}^{-}$in the bulk REM solutions).

Fig. 12 shows the calculated $\mathrm{pH}$ distribution as a function of distance from the center of a dealloyed S phase IMC perpendicular to the surface, based on Eq. 4. A maximum pH of about 10 appears at the center of the IMC, which is consistent with experimental data. ${ }^{37}$ As expected, $\mathrm{pH}$ decreases slowly as $\mathrm{R}_{\mathrm{x}}$ increases. This model assumes that all of the $\mathrm{OH}^{-}$generated originates at a single point in the center of the IMC, leading to poor modeling values for the concentration of $\mathrm{OH}^{-}$as $\mathrm{R}_{\mathrm{x}}$ approaches zero. However, for $\mathrm{R}_{\mathrm{x}} \geq 2.5 \mu \mathrm{m}$ (the assumed radius of the IMC surface), the model provides a reasonable estimate of the $\mathrm{pH}$ at $\mathrm{R}_{\mathrm{x}}$. Furthermore, although this model fails for $\mathrm{R}_{\mathrm{x}}<2.5 \mathrm{um}$, clearly the $\mathrm{pH}$ in the volume wherein $\mathrm{R}_{\mathrm{x}}<2.5$ um would be greater than the $\mathrm{pH}$ at distances wherein $\mathrm{R}_{\mathrm{x}}>2.5 \mathrm{um}$.

The critical $\mathrm{pH}$ for $\mathrm{Ce}(\mathrm{OH})_{3}$ precipitation in $4 \mathrm{mM} \mathrm{Ce}^{3+}$ solution is 8.2 , corresponding to an $\mathrm{R}_{\mathrm{x}}$ value of $9 \mu \mathrm{m}$. Therefore, the $\mathrm{pH}$ in the immediate vicinity of the IMC would clearly be high enough to induce $\mathrm{Ce}(\mathrm{OH})_{3}$ precipitation under steady-state conditions. Likewise, $\mathrm{La}(\mathrm{OH})_{3}$ and $\operatorname{Pr}(\mathrm{OH})_{3}$, which both have smaller solubility product constants than $\mathrm{Ce}(\mathrm{OH})_{3}$, would also precipitate on $\mathrm{S}$ phase.

As shown in Fig. 2, of all the IMCs, dealloyed $S$ phase exhibits the largest cathodic current density in $\mathrm{NaCl}$ solution and in the REM 


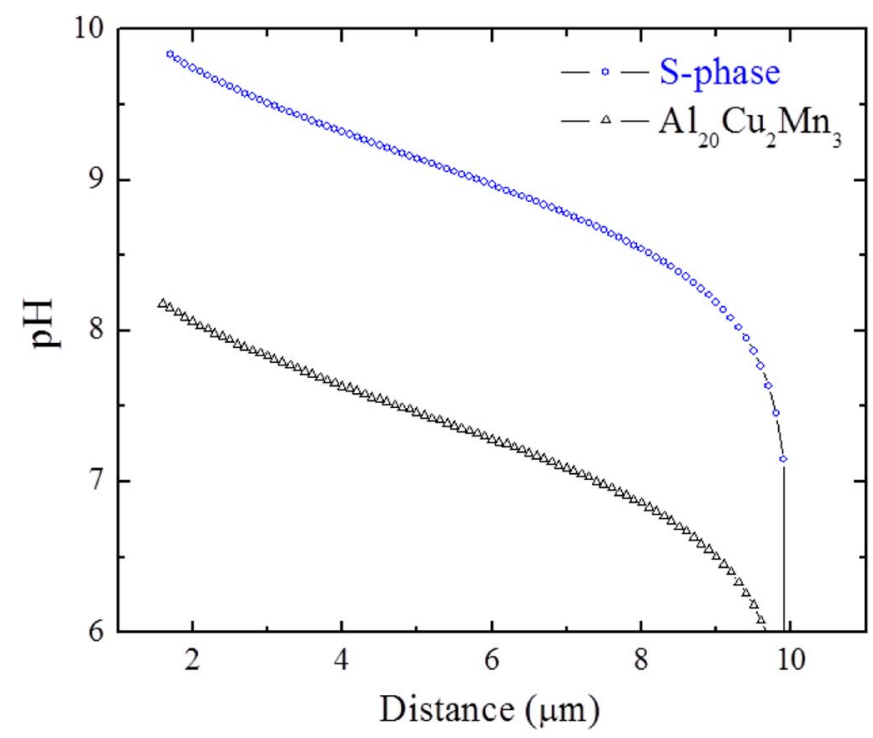

Figure 12. $\mathrm{pH}$ distribution around dealloyed $\mathrm{S}$ phase and an $\mathrm{Al}_{20} \mathrm{Cu}_{2} \mathrm{Mn}_{3}$ particle in $0.1 \mathrm{M} \mathrm{NaCl}$ based on the model in Fig. 11.

solutions. The current density on synthesized dealloyed S phase is about two or three orders of magnitude larger than that observed on the synthesized IMCs, $\mathrm{Al}_{7} \mathrm{Cu}_{2} \mathrm{Fe}$ and $\mathrm{Al}_{20} \mathrm{Cu}_{2} \mathrm{Mn}_{3}$. These two synthesized IMCs were used to represent the behavior of the compositionally variant $\mathrm{Al}-\mathrm{Cu}-\mathrm{Mn}-\mathrm{Fe}$ type particle class found in the alloy. A second calculation was performed using the above model with the limiting current density measured on synthesized $\mathrm{Al}_{20} \mathrm{Cu}_{2} \mathrm{Mn}_{3}$ in $\mathrm{NaCl}$ solution. As can be seen in Fig. 12, the ORR on $\mathrm{Al}_{20} \mathrm{Cu}_{2} \mathrm{Mn}_{3}$ is sufficient to provide the required $\mathrm{pH}$ minimum near the surface of the IMC, however, the overall lower $\mathrm{pH}$ distribution predicted over $\mathrm{Al}_{20} \mathrm{Cu}_{2} \mathrm{Mn}_{3}$ would be expected to lead to less precipitation on $\mathrm{Al}_{20} \mathrm{Cu}_{2} \mathrm{Mn}_{3}$ than on $\mathrm{S}$ phase. Indeed, $\mathrm{Ce}(\mathrm{OH})_{3}$ precipitation based on this model agrees with the observed precipitation of $\mathrm{Ce}(\mathrm{OH})_{3}$ on these two types of IMCs. EDS analysis of S phase and $\mathrm{Al}-\mathrm{Cu}-\mathrm{Mn}-\mathrm{Fe}$ type particles in AA2024-T3 exposed for 50.0 hours in a $\mathrm{CeCl}_{3}$ solution revealed 1.64 to $9.62 \mathrm{wt} \%$ cerium on $\mathrm{S}$ phase particles but only a very weak cerium signal was observed on $\mathrm{Al}-\mathrm{Cu}-\mathrm{Mn}-\mathrm{Fe}$ type particles.

To more closely study the relationship between the ORR on IMCs and the associated amount of precipitation, EDS mapping of $\mathrm{S}$ phase and $\mathrm{Al}-\mathrm{Cu}-\mathrm{Mn}-\mathrm{Fe}$ type particles in AA2024-T3 after 52.5 hours of exposure in the $\mathrm{CeCl}_{3}$ solution was performed. Figs. 13a and 13b show the surface morphology of an exposed $\mathrm{S}$ phase particle and an $\mathrm{Al}-\mathrm{Cu}-\mathrm{Mn}-\mathrm{Fe}$ type particle, respectively, while Figs. 13c and $13 \mathrm{~d}$ show the cerium distribution on the two IMCs. This mapping clearly reveals a higher cerium concentration on $\mathrm{S}$ phase than on $\mathrm{Al}-\mathrm{Cu}-$ $\mathrm{Mn}-\mathrm{Fe}$ particles. The high coverage on $\mathrm{S}$ phase is in agreement with both the above model and the $\mathrm{Ce}(\mathrm{OH})_{3}$ cap previously observed on a different exposed $\mathrm{S}$ phase particle (Fig. 8c). Cerium concentrations on both these IMCs are larger than that found on the matrix, which can be linked to the cathodic role of these IMCs in localized corrosion and the associated $\mathrm{pH}$ increase. Integration of the cerium peak areas corresponding to spectra acquired from each pixel mapped on the $\mathrm{S}$ phase particle was $2.0 \times 10^{6}$ counts. The total $S$ phase particle area was $236.4 \mu \mathrm{m}^{2}$ and, therefore, a resulting cerium peak area density of 8400 counts $/ \mu \mathrm{m}^{2}$ was observed. Integration of the cerium peak areas mapped on the Al-Cu-Mn-Fe type particle totaled $7.2 \times 10^{5}$ counts. With a total surface area of $183.7 \mu \mathrm{m},{ }^{2}$ this results in a cerium peak area density of 3800 counts $/ \mu \mathrm{m}^{2}$.

From the cathodic polarization curves in a $\mathrm{NaCl}$ solution (Fig. 2) acquired on synthesized IMCs, the cathodic limiting current density on $\mathrm{Al}_{7} \mathrm{Cu}_{2} \mathrm{Fe}$ and $\mathrm{Al}_{20} \mathrm{Cu}_{2} \mathrm{Mn}_{3}$ was found to be 29 and $54 \mu \mathrm{A} / \mu \mathrm{m}^{2}$, respectively. (As noted above, these two IMCs most closely represent the $\mathrm{Al}-\mathrm{Cu}-\mathrm{Mn}-\mathrm{Fe}$ type particles found in the alloy.) The cathodic

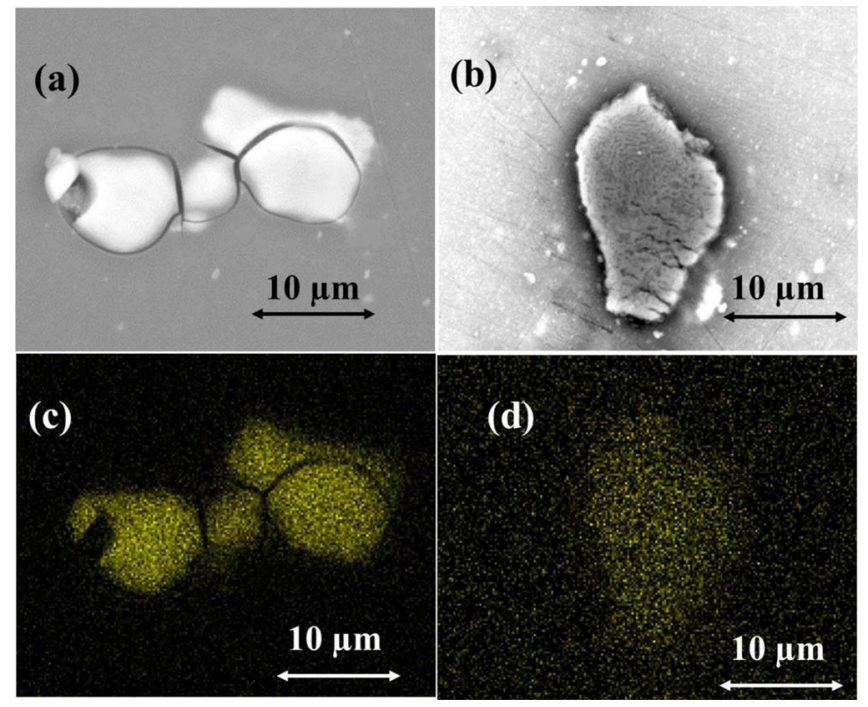

Figure 13. Ce analysis (EDS) on $\mathrm{S}$ phase and an $\mathrm{Al}-\mathrm{Cu}-\mathrm{Mn}-\mathrm{Fe}$ type particle after 52.5-hour exposure in a $\mathrm{CeCl}_{3}$ solution: (a) and (b) are corrosion morphology ((a) is BSE image); (c) and (d) are Ce mapping data obtained by EDS on the particles in (a) and (b).

limiting current density obtained from cathodic polarization curves of dealloyed $\mathrm{S}$ phase in $\mathrm{NaCl}$ solution was $3750 \mu \mathrm{A} / \mu \mathrm{m}^{2}$, which is more than 100 times higher than that on $\mathrm{Al}_{7} \mathrm{Cu}_{2} \mathrm{Fe}$ and 70 times higher than that on $\mathrm{Al}_{20} \mathrm{Cu}_{2} \mathrm{Mn}_{3}$. Despite this significantly higher current density (and, therefore, higher generation of $\mathrm{OH}^{-}$), the cerium peak area density observed on S phase was only 2.2 times that observed on Al$\mathrm{Cu}-\mathrm{Mn}-\mathrm{Fe}$ type particles. This can be attributed to two aspects of the precipitation reaction. First, the cubic dependence of the concentration of $\mathrm{OH}^{-}$on the solubility product constant, combined with the lower $\mathrm{pH}$ values surrounding an $\mathrm{Al}-\mathrm{Cu}-\mathrm{Mn}-\mathrm{Fe}$ particle would lead to an exponential drop in $\mathrm{Ce}(\mathrm{OH})_{3}$ precipitation over an $\mathrm{Al}-\mathrm{Cu}-\mathrm{Mn}-\mathrm{Fe}$ type particle versus an $\mathrm{S}$ phase particle. Second, as the initially strongly driven ORR delivers $\mathrm{Ce}(\mathrm{OH})_{3}$ onto $\mathrm{S}$ phase, the kinetics of the ORR at $\mathrm{S}$ phase would be expected to decrease and the delivery of $\mathrm{Ce}(\mathrm{OH})_{3}$ should also decrease with time.

Slowness of inhibition by rare earth metal inhibitors on AA2024T3.- Assuming inhibition by REM inhibitors arises from local hydroxide precipitation, an increase in $\mathrm{pH}$ is required; at least in the vicinity of IMCs. The $\mathrm{pH}$ increase at cathodic sites is caused by the ORR, which must be accompanied by unwanted anodic dissolution. As a result, the inhibition provided by REM inhibitors is "slow" to initiate, and likely does not initiate until some corrosion has occurred. This slow inhibition is mainly demonstrated on the S-phase particles in AA2024-T3 alloy.

In the case of $\mathrm{S}$ phase, which is initially an active anode and subsequently an active cathode, polarization measurements on synthesized $S$ phase indicate that REM inhibitors did not provide significant inhibition on anodic kinetics (Fig. 1e). REM inhibition of the initial dealloying process of $\mathrm{S}$ phase is not expected since this dealloying corrosion primarily involves the dissolution of active elements instead of the ORR. Therefore, the local $\mathrm{pH}$ increase is limited and hydroxide precipitation is expected to be slow. However, as $\mathrm{Al}$ and $\mathrm{Mg}$ corrode and a $\mathrm{Cu}$-rich layer forms, the ORR occurs at a much higher rate, as can be seen in the cathodic polarizations curves of $\mathrm{S}$ phase which was allowed to dealloy before commencement of the cathodic polarization scans (Fig. 2e). This high ORR rate, in turn, leads to a high local $\mathrm{pH}$ near the surface of $\mathrm{S}$ phase particles. The increased $\mathrm{pH}$ around a dealloyed $\mathrm{S}$ phase particle is high enough to induce hydroxide formation (Fig. 12). Along with the ORR occurring on S phase, anodic dissolution of the surrounding matrix occurs. Inhibition of this matrix dissolution and initial dealloying of S-phase particle is 
not observed, which demonstrates the slow inhibition process of REM inhibitors. Similar slow inhibition is also expected on $\mathrm{Al}-\mathrm{Cu}-\mathrm{Mn}-\mathrm{Fe}$ type particles; however, the anodic dissolution of the surrounding matrix is modest due to their lower cathodic kinetics compared to that on dealloyed $\mathrm{S}$ phase.

Therefore, paradoxically, effective protection arising from REM inhibitors strongly depends on how much the corrosion process proceeds before hydroxide formation occurs. This dependence is closely related to the ORR on cathodic sites, the corrosion resistance of second phase particles, and the solubility products of hydroxide phases that form.

\section{Conclusions}

1. REMs $\left(\mathrm{Ce}^{3+}, \mathrm{Pr}^{3+}\right.$, and $\left.\mathrm{La}^{3+}\right)$ do not show obvious effects on $\mathrm{E}_{\text {corr }}$, $\mathrm{E}_{\mathrm{pit}}$ and $\mathrm{i}_{\text {corr }}$ in short-term polarization experiments on synthesized IMC particles, suggesting that they are not effective intrinsic anodic inhibitors.

2. All REMs inhibit ORR kinetics on synthesized IMCs, but to different extents. $\mathrm{Pr}^{3+}$ is found to be the most effective, and its effect on $\mathrm{Al}_{20} \mathrm{Cu}_{2} \mathrm{Mn}_{3}$ and $\mathrm{Al}-4 \% \mathrm{Cu}$ is comparable to chromate inhibition. $\mathrm{Pr}^{3+}$ 's higher efficiency relative to $\mathrm{Ce}^{3+}$ and $\mathrm{La}^{3+}$ is attributed to $\mathrm{Pr}^{3+}$ 's low solubility product constant.

3. REMs do not inhibit the initial dealloying of S phase in AA2024$\mathrm{T} 3$, but after dealloying transforms $\mathrm{S}$ phase from an anode to a cathode and a $\mathrm{Cu}$-rich layer forms, REMs precipitate on the surface and inhibit subsequent dealloying and trenching corrosion.

4. $\mathrm{Ce}(\mathrm{OH})_{3}$ precipitation layers formed on $\mathrm{S}$ phase in AA2024-T3 alloy grow slowly, but appreciably, in the initial stage ( $\sim 1$ hour) of exposure to $\mathrm{Ce}^{3+}$ solution, with little increase observed during an additional 50 hours of exposure indicating a slowing precipitate formation once the layer is thick enough to inhibit the ORR. The presumably porous $\mathrm{Ce}(\mathrm{OH})_{3}$ layer that forms appears to retard corrosion, but not completely stop it.

5. A modeled $\mathrm{pH}$ distribution around a dealloyed $\mathrm{S}$ phase particle in $0.1 \mathrm{M} \mathrm{NaCl}$ indicates that the ORR at this particle leads to a $\mathrm{pH}>9.6$ in the region immediately above the particle surface $(<2.5 \mu \mathrm{m})$ and that the $\mathrm{pH}$ remains above 8.2 to a distance of $9 \mu \mathrm{m}$ away from the particle surface. These $\mathrm{pH}$ values are more than sufficient to induce precipitation of REM hydroxides in $4.0 \mathrm{mM}$ REM solutions. A modeled $\mathrm{pH}$ distribution around an $\mathrm{Al}_{20} \mathrm{Cu}_{2} \mathrm{Mn}_{3}$ particle in $0.1 \mathrm{M} \mathrm{NaCl}$ also supports precipitation of REM hydroxides in $4.0 \mathrm{mM}$ REM solutions, albeit at much lesser rates than predicted at an $\mathrm{S}$ phase particle. Exposure experiments combined with EDS analysis support the validity of the model.

6. REMs are 'slow' inhibitors compared to chromate. Their inhibition efficiency is dependent on the interplay between how fast corrosion occurs and how fast REM precipitation occurs.

\section{Acknowledgments}

This research is sponsored by the U.S. Air Force Academy under agreement number FA7000-12-2-0015. The U.S. Government is authorized to reproduce and distribute reprints for Governmental purposes notwithstanding any copyright notation thereon. The views and conclusion contained herein are those of the authors and should not be interpreted as necessarily represented official policies or endorse- ment, either expressed or implied, of the U.S. Air Force Academy or the U.S. Government.

\section{References}

1. J. E. Hatch, Aluminum: properties and physical metallurgy, American Society for Metals, Metals Park, Ohio (1984)

2. L. F. Mondolfo, Aluminum alloys: structure and properties, p. 971, Butterworths, London (1976).

3. A. E. Hughes et al., Surf. Interface Anal., 42, 334 (2010).

4. A. Boag, A. E. Hughes, A. M. Glenn, T. H. Muster, and D. McCulloch, Corros. Sci., 53, 17 (2011).

5. R. G. Buchheit, J. Electrochem. Soc., 142, 3994 (1995)

6. N. Birbilis and R. G. Buchheit, J. Electrochem. Soc., 152, B140 (2005)

7. P. Leblanc and G. S. Frankel, J. Electrochem. Soc., 149, B239 (2002)

8. P. Schmutz and G. S. Frankel, J. Electrochem. Soc., 145, 2295 (1998)

9. P. Schmutz and G. S. Frankel, J. Electrochem. Soc., 145, 2285 (1998).

10. J. Li, B. Hurley, and R. Buchheit, J. Electrochem. Soc., 162, C219 (2015).

11. O. A. Omotosho, J. O. Okeniyi, and O. O. Ajayi, J. Fail. Anal. Prev., 10, 408 (2010).

12. J. K. Hawkins et al., Corros. Sci., 27, 391 (1987).

13. M. A. Heine and M. J. Pryor, J. Electrochem. Soc., 114, 1001 (1967).

14. J. Zhao, G. Frankel, and R. L. McCreery, J. Electrochem. Soc., 145, 2258 (1998),

15. L. Xia, E. Akiyama, G. Frankel, and R. McCreery, J. Electrochem. Soc., 147, 2556 (2000).

16. G. O. Ilevbare and J. R. Scully, Corrosion, 57, 134 (2001).

17. B. R. W. Hinton and L. Wilson, Corros. Sci., 29, 967 (1989)

18. B. R. W. Hinton, D. R. Arnott, and N. E. Ryan, Met. Forum, 7, 211 (1984).

19. D. R. Arnott, N. E. Ryan, B. R. W. Hinton, B. A. Sexton, and A. E. Hughes, Appl. Surf. Sci., 22-3, 236 (1985).

20. B. R. W. Hinton, J. Alloys Compd., 180, 15 (1992)

21. A. K. Mishra and R. Balasubramaniam, Corros. Sci., 49, 1027 (2007).

22. N. Birbilis, R. G. Buchheit, D. L. Ho, and M. Forsyth, Electrochem. Solid State Lett., 8, C180 (2005).

23. F. Mansfeld and Y. Wang, Mater. Sci. Eng. A, 198, 51 (1995).

24. D. R. Arnott, B. R. W. Hinton, and N. E. Ryan, Corrosion, 45, 12 (1989)

25. K. A. Yasakau, M. L. Zheludkevich, S. V Lamaka, and M. G. S. Ferreira, J. Phys. Chem. B, 110, 5515 (2006).

26. L. Paussa, F. Andreatta, N. C. R. Navarro, A. Duran, and L. Fedrizzi, Electrochim Acta, 70, 25 (2012).

27. L. Paussa, F. Andreatta, D. De Felicis, E. Bemporad, and L. Fedrizzi, Corros. Sci. (2013).

28. F. Andreatta et al., Corros. Sci., 65, 376 (2012).

29. R. G. Buchheit, S. B. Mamidipally, P. Schmutz, and H. Guan, Corrosion, 58, 3 (2002)

30. A. E. Hughes, R. J. Taylor, B. R. W. Hinton, and L. Wilson, Surf. Interface Anal., 23, 540 (1995).

31. C. Wang, F. Jiang, and F. Wang, Corrosion, 60, 237 (2004).

32. P. Campestrini, H. Terryn, A. Hovestad, and J. H. de Wit, Surf. Coatings Technol., 176, 365 (2004).

33. Y. Xingwen, C. Chunan, Y. Zhiming, Z. Derui, and Y. Zhongda, Mater. Sci. Eng. A, 284, 56 (2000).

34. T. Suter and H. Bohni, Electrochim. Acta, 47, 191 (2001).

35. R. G. Buchheit, R. P. Grant, P. F. Hlava, B. Mckenzie, and G. L. Zender, J. Electrochem. Soc., 144, 2621 (1997).

36. R. G. Buchheit, M. A. Martinez, and L. P. Montes, J. Electrochem. Soc., 147, 119 (2000).

37. M. B. Vukmirovic, N. Dimitrov, and K. Sieradzki, J. Electrochem. Soc., 149, B428 (2002).

38. N. Dimitrov, J. A. Mann, M. Vukmirovic, and K. Sieradzki, J. Electrochem. Soc., 147, 3283 (2000).

39. K. D. Ralston, T. L. Young, and R. G. Buchheit, J. Electrochem. Soc., 156, C135 (2009).

40. M. K. Cavanaugh, J.-C. Li, N. Birbilis, and R. G. Buchheit, J. Electrochem. Soc., 161, C535 (2014)

41. N. Birbilis and R. G. Buchheit, J. Electrochem. Soc., 155, C117 (2008).

42. N. A. Lange and J. G. Speight, Lange's handbook of chemistry, 16th ed., p. 1v. (various pagings), McGraw-Hill, inc, New York (2005).

43. K. A. Yasakau, M. L. Zheludkevich, and M. G. S. Ferreira, J. Electrochem. Soc., 155 C169 (2008).

44. E. Samson, J. Marchand, and K. A. Snyder, Mater. Struct., 36, 156 (2003).

45. L. Yuan-Hui and S. Gregory, Geochim. Cosmochim. Acta, 38, 703 (1974). 